\title{
What the Global Patent System Needs Now
}

\begin{abstract}
What the global patent system needs now is the global consensus necessary to evolve. It needs to commit to further develop patent law's existing institutions to produce a properly integrated international system to replace the patchwork of inefficient and cumbersome national systems that exist presently. What the global patent system needs is to replace the current system of nation states maintaining separate national patent offices, granting nationa patents and enforcing patents individually in national courts with a properly integrated international system. Such a properly integrated international system is one whereby an international patent office grants unitary patents that are recognized and enforceable in all countries of the world.
\end{abstract}

\section{Introduction}

One could be forgiven for thinking that the success of the Patent Cooperation Treaty (PCT) system would logically (and swiftly) lead to the development of a properly integrated international patent system. This has not, at least as yet, been the stepping-stone some many have envisaged it to be because the necessary consensus between nation states as to the further advancement of the patent system is wanting.

Obtaining patents is difficult and time-consuming, and as a consequence, is costly. It diverts valuable time and resources from those with the means to invent and those with the means to commercialize inventions, both of whom are necessary to bring the new products and processes to the public.

The PCT introduced a streamlined means of seeking patent protection in a number of countries. Rather than a patent applicant filing separate patent applications in each and every country in which he or she seeks protection (as was previously necessarily), the PCT makes it possible to seek patent protection for an invention simultaneously in any number of the PCT's 150 member states by filing a single "international" patent application. A PCT application does not result in an "international patent" being granted as the decision as to whether to grant, and the granting of patents, remains under the control of the national or regional patent offices in what is called the PCT's national phase.

The PCT is an incremental step that has reduced the complexity and cost of obtaining patent protection in a number of nation states. The PCT itself builds on the international consensus that led to the formation of the Paris Convention for the Protection of Industrial Property of 1883 (the world's first treaty devoted to intellectual property matters), which made it easier to apply for patent protection on a country-by-country basis. Before the Paris Convention, patent applicants needed to arrange to simultaneously submit patent applications in each country in which they sought protection, otherwise the first application would anticipate any subsequently submitted applications, rendering them not novel. Similarly, the European Patent Convention, like the PCT, provides a simplified and

\section{Journal of Clinical Trials \& Patenting}

\author{
Ben McEniery* \\ Faculty of Law, Queensland University of Technology, Australia \\ *Address for Correspondence:
}

Ben McEniery, Faculty of Law, Queensland University of Technology; Barrister-at-Law, Brisbane, Australia, E-mail: b.mceniery@qut.edu.au

Submission: 24 November, 2016

Accepted: 21 December, 2016

Published: 26 December, 2016

Copyright: $\odot 2016$ McEniery B. This is an open access article distributed under the Creative Commons Attribution License, which permits unrestricted use, distribution, and reproduction in any medium, provided the original work is properly cited.

more cost effective path to applying for patents in many jurisdictions, but not a single unitary patent. The grant by the European Patent Office of a European Patent results in a bundle of national patents, each of which can be enforced in the relevant EPC Contracting State.

The current system of nation states maintaining separate national patent offices, granting national patents and enforcing patents individually in national courts is hopelessly inefficient, wasteful in its duplication and operates as a tax on innovation. That tax on innovation is then a barrier that, at worst, deprives the world of new and useful products and processes that enrich and simplify our lives, and at best, delays our access to them. While there are some exceptions to this territorialism, such as the African Intellectual Property Organization (OAPI) and the European Patent Convention, for the most part the role and function of patents is a strictly national affair.

Even with the PCT and the Paris Convention (and arrangements like the EPC), the exorbitant costs of obtaining and enforcing patents in multiple countries makes obtaining global patent protection or patent protection in more than a handful of countries possible for only the wealthiest multinational companies [1]. This is foremost a result of the need for patent applicants to seek patents in each and every country in the world in which protection is desired, and to enforce each and every patent separately in countries in which an infringement has occurred. The data indicates that inventors choose only a small number of jurisdictions in which to patent and on average file in fewer than four countries [2].

There are of course many factors that determine in which countries a patentee will seek to patent. For instance, in some cases (such as where the invention is a pharmaceutical substance), patents will only be sought in countries where significant production capacity exists. Alternatively, patents might only be sought in places where the patentee considers that there is a sufficient market for the invention. However, in many cases, the marginal cost of seeking to patent in each additional jurisdiction will undeniably be a factor. If those inventors or patentees can only afford to patent in a select number of jurisdictions, then they have little incentive to commercialize and market those inventions in jurisdictions in which they do not have patent protection. This is a serious impediment to innovation and a 
serious access to justice issue.

The decision as to which jurisdictions a patentee will seek to patent in will be subject to many factors, including what the inventions and what production capacity competitors may have. The marginal cost of seeking to patent in each additional jurisdiction will likewise be a factor.

Implementing a system of this kind would of course require substantive patent law harmonization and use of one or more common languages. While national patent laws around the globe are largely uniform, the international treaties upon which those national laws are based give a large degree of flexibility to national legislatures to decide how they will implement their international obligations. For instance, the World Trade Organization's TradeRelated Intellectual Property Rights Agreement (TRIPS Agreement) imposes only broadly stated minimum standards to which national domestic laws must conform. Those minimum standards concern matters such as the scope of patentable subject matter of patents, the requirements of novelty and inventiveness, the term of protection, and enforcement mechanisms. It is otherwise designed to permit countries to implement their patent systems in a way that they believe supports their national development goals.

A recent, but failed attempt at substantive patent law harmonization is the Substantive Patent Law Treaty (SPLT). It would have removed most of the remaining national flexibility in patent systems and paved the way for a unitary international patent granted directly by the World Intellectual Property Organization (WIPO) [3].

Creating a unified global patent system and a properly resourced international patent office is the best way to address patent application pendency, being the delay between a patent application being filed and a patent being granted due to backlogs in the queue of patent applications waiting to be examined. These delays are caused by patent office's not being adequately staffed or resourced to deal with the increased volume of patent applications they receive caused by the growth in innovation and the resulting increase in patent applications being filed. Backlogs are a problem in many patent offices.

More importantly, it is a means of increasing access to new technological innovation.

\section{The impediment: a lack of international consensus}

What has changed since the introduction of the PCT is that the tussle between developed and developing countries has become more pronounced. The global north and south have completely disparate views as to what benefits the patent system should provide to their citizens. This is part of a larger breakdown in consensus, exemplified by the failed July 2008 Doha Development Agenda (DDA) negotiations in relation to agriculture, industrial tariffs and non-tariff barriers. The most significant differences was between developed nations led by the European Union (EU), the United States (USA), and Japan and the major developing countries led by India, Brazil, China, and South Africa [4]. As a consequence, efforts at achieving substantive law harmonization of patent laws have been stifled.

The lack of consensus is not just limited to disunity between developed and developing nations. Indeed in Europe, the proposed European Unitary Patent scheme, which allows for a single unitary patent enforceable in all participating European Union states that are parties to the Agreement on a Unified Patent Court seems to have failed [5]. That failure seemingly preceded United Kingdom's exit (or Brexit) from the European Union and will likely be exacerbated by it.

Instead of taking bold steps towards forming a properly integrated global patent system, the world's leading IP offices are today working to make progress towards procedural harmonization which will reduce the cost of seeking patent protection. These generally take the form of administrative collaborations between national patent offices and regional patent offices for the purpose of sharing and relying on each other's search and examination results. These programs, usually bilateral or trilateral (and of which there are many), are created with the aim of reducing the time taken to examine patent applications and inconsistencies between examination results in different patent offices. In short, these arrangements seek to rely on collaboration to produce more reliable patent examination results more quickly and cost-effectively than would be produced by patent examiners working independently.

This has taken the form of "work sharing" among the three "trilateral" patent offices (the USPTO, Japan's Patent Office and the European Patent Office) and a small number of additional technologically developed countries such as Canada, Australia, South Korea, Singapore, and more recently, China (which now receives more patent applications that any other country). What "work sharing" means is the sharing of prior art search and examination results, which is useful when the same patent application (or patent applications with minor variations to account for local laws or practises) is considered in multiple jurisdictions. One example of these developments is the considerable number of collaborative Patent Prosecution Highway ("PPH") programs that have been negotiated between various patent offices [6].

These are incremental and worthy goals that are attainable in the shorter-term, which will reduce the barriers to entry to all innovators, particularly through a reduction in administrative costs. While work sharing is a step in the right direction, it does not deliver the efficiencies sought in the article. For one, it does not relieve a patent applicant of the burden and expense of navigating the application process in each jurisdiction in which patent protection is sought. The patent is still examined in each of those jurisdictions; but the patent examiners in each of those jurisdictions has the ability to rely on and build upon the work of examiners in other patent office's who have previously encountered a corresponding application.

However, what also is needed is a bold jump from nationally focused systems to a fully integrated global patent system that truly serves the needs of all inventions, from multinationals to small to medium-sized enterprises to individuals.

\section{The next logical step}

It is submitted that the next logical step in further developing the procedural advantages won by the introduction of the PCT and the Paris Convention is a new international treaty to that permits a single international patent application that upon grant results in a unitary international patent enforceable in all member states.

Such an application would be filed in an international patent 
office that is independent of international patent systems and individual nation states. That international patent office would be a central administration empowered to examine all patent applications in accordance with a uniform patentability standard. It would also necessarily have the sole power, to the exclusion of member states, to centrally administer all patent examinations and also all pre-grant opposition and post-grant revocation challenges (with rights of appeal to an international patent court).

The international patent court would provide an avenue of appeal from the international patent office, the sole role of which is to hear appeals from the international patent office on pre- and post-grant oppositions, but not infringement suits.

Matters of patent infringement and enforcement would remain the exclusive domain of member states and their courts (thus allowing member states to retain a degree of sovereignty). This would permit the hearing of multi-national cross-border patent disputes in a single national court and would necessarily be coupled with a coordination of parallel proceedings involving the same parties and patent.

\section{Conclusion}

A unified global patent system is not a new idea [7]. The World Intellectual Property Organization (WIPO) had tried to achieve this goal. More recently, intellectual property issues have formed part of the World Trade Organization negotiations, which allowed intellectual property law harmonization to be coupled with issues of trade and tariffs.

The path to a global patent system will be a gradual one. Perhaps the road to achieving the necessary consensus might not best achieved by conducting negotiations between all possible contracting states, but instead between a few select countries. Meller has made the same suggestion, noting that the 1883 Paris Convention was arrived at by achieving consensus among patent conscious countries before being later adopted across the world [8].

The obvious impediment to the implementation of a properly integrated international patent system is the present lack of international consensus as to what sort of inventions ought to be patentable and what the direction of the patent system ought to be. The implementation of such a system would require a huge jump from the current system in which national patents are granted by national patent offices and separately enforced in national courts, but the current system is deeply flawed.

One likely trade off to achieve the necessary consensus would appear to be to respond to pressure from developing countries to agree to expand the scope of compulsory licensing beyond just replication of pharmaceuticals needed to respond to health emergencies.

While many obstacles stand in the way of substantive patent law harmonization [9], it is submitted that the need to make global patenting more accessible, improve patent quality and the availability of patent and prior art information, and to improve the efficiency of patent enforcement by allowing cross-border patent disputes to be consolidated in national courts. The failure to find the consensus necessary to embrace implement such a system unjustifiably harms those who create new technology. It also harms the users of technology, including those in developing countries, because it delays people taking advantage of the trickle down benefits of innovation, because it delays access to new ideas.

\section{References}

1. Trimble M (2012) Global patents: limits of transnational enforcement. Oxford University Press, USA. pp. 248.

2. World Intellectual Property Organization (2016) Patent cooperation treaty yearly review: The international patent system.

3. Reichman JH, Dreyfuss RC (2007) Harmonization without consensus: Critical reflections on drafting a substantive patent law treaty. Duke Law J 57: 85-130.

4. Wilkinson R, Hannah E, Scott J (2016) The WTO in Nairobi: the demise of the Doha development agenda and the future of the multilateral trading system. Global Policy 7: 247-255.

5. Mahne K (2012) A unitary patent and unified patent court for the european union: an analysis of europe's long standing attempt to create a supranational patent System. J Pat Trademark Off Soc'y 94: 162.

6. Pitts A, Kim J (2009) Patent prosecution highway: is life in the fast lane worth the cost. 1 Hastings Sci Tech L J 127.

7. Mossinghoff GJ, Kuo VS (1998) World patent system circa 20XX A.D.*. 38 IDEA 529.

8. Meller MN (1998) Planning for a Global patent system. J Pat Trademark Off Soc'y 80: 379-391.

9. Sabatelli A, Rasser JC (1995) Impediments to global patent law harmonization. N Ky L Rev 22: 579. 